\title{
Formation of p-n Junctions in Nanoparticle Cerium Oxide Electrolytic Cells Displaying Memristive Switching Behaviour
}

\author{
Rafaela Cristina De Carvalho \\ Technological University Dublin, rafa_cdc@hotmail.com \\ Tony Betts \\ Technological University Dublin, anthony.betts@tudublin.ie \\ John Cassidy \\ Technological University Dublin, john.cassidy@tudublin.ie
}

Follow this and additional works at: https://arrow.tudublin.ie/scschcpsart

Part of the Chemistry Commons

\section{Recommended Citation}

de Carvalho, R.C., Betts, T. \& Cassidy, J.F. (2020) Formation of p-n Junctions in Nanoparticle Cerium Oxide Electrolytic Cells Displaying Memristive Switching Behaviour, Phys. Chem. Chem. Phys., 2020,22,

4216-4224 . DOI:10.1039/C9CP06016B

This Article is brought to you for free and open access by the School of Chemical and Pharmaceutical Sciences at ARROW@TU Dublin. It has been accepted for inclusion in Articles by an authorized administrator of ARROW@TU Dublin. For more information, please contact arrow.admin@tudublin.ie, aisling.coyne@tudublin.ie, gerard.connolly@tudublin.ie.

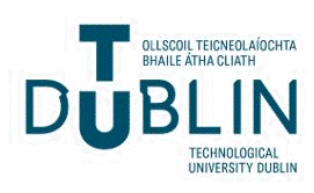




\title{
Formation of p-n Junctions in Nanoparticle Cerium Oxide Electrolytic Cells Displaying Memristive Switching Behaviour
}

\author{
Rafaela C. de Carvalho ${ }^{\mathrm{a}, \mathrm{b}}$, Anthony J. Betts ${ }^{\mathrm{a}, \mathrm{c}}$, John F. Cassidy ${ }^{\mathrm{a}, \mathrm{b}}$
}

A macro-scale metal-semiconductor-metal device comprising $\mathrm{CeO}_{2}$ nanoparticles cast from a suspension of cerium dioxide formed by a novel synthetic method was fabricated. Thin $\mathrm{CeO}_{2}$ films of $40 \mathrm{~nm}$ thickness placed between panels of aluminium and/or copper displayed memristive-like resistive switching behaviour upon the application of potential sweeps ranging between $-0.6 \mathrm{~V}$ and $0.6 \mathrm{~V}$. A mechanism is proposed based on the notion that an electrolytic cell operates under such conditions with the initial formation of $\mathrm{p}$ and n-type regions within the central semiconductive thin film. Evidence is presented for the existence of numerous point defects in these nanosized $\mathrm{CeO}_{2}$ films, which are also likely to play a role in the device's operation acting as internal dopants. Steady currents were observed upon the imposition of constant potentials, most notably at higher potential values (both anodic and cathodic). It is suggested that electrons and holes act as charge carriers in these devices rather than ionic species as proposed in some other mechanisms.

\section{Introduction}

Resistive Random-Access Memory (RRAM also known as ReRAM) is a resistive switching memory and has been proposed as one of the next generation of non-volatile memory technologies for the computing industry. It is normally constructed from a metal/semiconductor/metal configuration (MSM), often with a transition metal oxide in the middle layer which is the origin of the resistive switching (RS) behaviour [1, 2]. Such resistive switching memory devices behave as memristors and can either operate upon the application of a sufficiently positive or a negative potential to effect a change in resistance (unipolar switches) or may act as bipolar switches. Bipolar resistance switching is dependent on the polarity of the applied voltage which is most often demonstrated by a potential ramp. Typical behaviour of bipolar resistance switching includes a 'figure of eight' current- potential (I-V) profile in the first and third quadrants of an I-V plot, along with a transition from a high resistance state (HRS) to a 
low resistance state (LRS) or vice versa [3]. This characteristic has the potential for use as a low energy memory storage device in computing and computer memory applications.

A number of different configurations have been reported in the last decade for the production of metal oxide memristive switching devices [4,5]. These include $\mathrm{NiO}$ [5], $\mathrm{ZnO}$ [6], along with $\mathrm{TiO}_{2}$, which is the material with the largest number of publications [7-10]. Cerium dioxide, $\mathrm{CeO}_{2}$ is another potential semiconductor material that can either be electrochemically deposited [11] or sputter coated [12]. There are however only limited reports on the fabrication of cerium dioxide (often referred to as cerium oxide) nanostructures for use in resistive-switching devices $[11,13,14]$.

Cerium, a lanthanide series element, exists in two common oxidation states, $\mathrm{Ce}^{3+}$ (e.g. in $\mathrm{Ce}_{2} \mathrm{O}_{3}$ ) and $\mathrm{Ce}^{4+}$ (e.g.in $\mathrm{CeO}_{2}$ ). The latter is more commonly used in catalytic applications due to the higher stability of the $\mathrm{Ce}^{4+}$ state over the $\mathrm{Ce}^{3+}$ state [15]. The non-stoichiometric form of $\mathrm{CeO}_{2}$ exhibits a broad range of stoichiometries, represented as $\mathrm{CeO}_{2-\mathrm{x}}$, where $\mathrm{x} \leq 0.28$ [16]. The crystal structure of $\mathrm{CeO}_{2}$ typically has a large oxygen deficiency (which increases with the decrease in the size of the nanoparticle), hence the reason for interest in the compound's nanostructure as reported by Younis et al. [11,17].

Several different mechanisms have been proposed for the operation of a memristor. One of the earliest was based on the production of high resistance (or semiconducting) nanosized layer such as $\mathrm{TiO}_{2}$ contiguous with a conducting (low resistance) layer [18-21]. This $\mathrm{TiO}_{2}$ layer model proposes that in order to promote a current-voltage hysteresis, the system requires a certain atomic reallocation that modulates the electronic current overtime during a potential sweep.

Depending upon the materials used, a number of different processes have also been implicated during memristive switching [22]. These include Mott (insulator-metal) transitions, Schottky barrier (semiconductor-metal) behaviour at electrode interfaces, charge trapping or de-trapping, polaron melting and ordering, electric field-induced generation of crystalline defects and the creation or destruction of conducting filaments through the thin film between both outer electrodes.

Conductive filament models have gained considerable support [8, 11, 12, 23-27]. In the Valence Change Model (VCM) it is proposed that oxygen vacancies can induce growth of a conductive strand or filament and thereby contribute to the charge transport [24-26]. In the Thermochemical Model (TCM) a high local temperature increase (up to $1000^{\circ} \mathrm{C}$ ) may result in formation of conductive filaments [28]. Another common filament model, the Electrochemical 
Metallisation Model (ECM) is based on the oxidation/reduction of metals/ions, resulting in the formation of conductive paths between both outer electrodes. The ECM has been suggested for the operation of RS devices with Ag and $\mathrm{Cu}$ electrodes. One problem with such filament models is the existence of an insulating layer adjacent to one electrode making charge transport through the solid-state electrolyte extremely difficult during the application of an electrical potential.

RS devices invariably operate at room temperature where electrical conductivity $(\sigma)$ in transition metal oxides, such as $\mathrm{TiO}_{2}$ is the sum of the product of both electron (n) and hole concentrations (p) and mobility terms ( $\mu_{\mathrm{n}}$ and $\mu_{\mathrm{p}}$ respectively) and is given by $\mathrm{e}\left(\mathrm{n} \mu_{\mathrm{n}}+\mathrm{p} \mu_{\mathrm{p}}\right)$ where e is the elementary charge [29]. Therefore, as such devices operate under ambient conditions, the ionic conductivity contribution will be insignificant. Ionic charge transport normally occurs at high temperatures in solid state electrolytes, usually in excess of several hundred degrees Celsius. In addition, if the mechanism of RS occurred due to movement of ionic species then the current produced should be expected to decay within a few seconds after switching potential. It has been proposed for a $\mathrm{TiO}_{2}$-based device that a constant current flow indicates p-n junction formation which plays a crucial role in the charge transport within the thin film [30]. In the case of Valence Change Memory (VCMs) memristor device models [28], oxygen vacancies formed at the anode are believed to migrate to the other electrode (cathode) and are responsible for the transition from a high resistance state (HRS) to a low resistance state (LRS) [9, 23]. Equivalent circuit models, resulting from impedance studies, have been reported for a $\mathrm{Pt} / \mathrm{TiO}_{2} / \mathrm{Pt}$ device [31], along with a comprehensive overview of various mechanisms [32].

Thus, although several models have been suggested to explain the resistance switching behaviour of metal oxides, there is still much debate regarding the nature of the charge carriers in these devices and their operational mechanism. For example, a review of conduction mechanisms of RS devices reported a wide range of different mechanisms, sometimes a different mechanism being proposed for the same device [33]. An alternative approach is to use electrochemical principles and the concepts of an electrolytic cell involving solid-state electrolyte processes within the semiconductor interlayer and at both outer electrode interfaces [34-39].

This paper describes the fabrication of a simple macro-scale nanoparticle $\mathrm{CeO}_{2}$-based memristive switching device using a facile drop cast method, involving a novel nanoceria synthesis. Utilising concepts concerning the operation of an electrolytic cell, together with wellknown point defect models of cerium dioxide and the well-established theory of electron and 
electron-hole carriers in semiconductors, a new model is proposed for the operation of cerium dioxide-based memristive switching assemblies [30, 40,41].

\section{Experimental}

\subsection{Synthesis and characterisation of $\mathrm{CeO}_{2}$}

All chemicals were purchased from Sigma and Acros Organics and were used as received without further purification. Cerium dioxide, $\mathrm{CeO}_{2}$ nanoparticles were prepared by precipitation in the absence of a capping agent by a novel precipitation method. Initially a solution of 0.1 $\mathrm{mol} / \mathrm{L} \mathrm{CeCl}_{3} .7 \mathrm{H}_{2} \mathrm{O}$ was prepared. This was then added dropwise to $2 \mathrm{~mol} / \mathrm{L}$ ammonia solution until a precipitate formed. Finally, purple $\mathrm{Ce}(\mathrm{OH})_{4}$ particles were produced. Excess ammonium was removed by washing with high purity water and then the supernatant liquid was removed after undergoing centrifugation several times. After that, $1 \mathrm{~mol} / \mathrm{L} \mathrm{HNO}_{3}$ was added dropwise to the suspension until a stable colloid was established. The resultant solution was then heated for 30 min at $60^{\circ} \mathrm{C}$ resulting in a yellow-coloured $\mathrm{CeO}_{2}$ nanoparticle hydrosol. The hydrosol was then placed in an oven at $200^{\circ} \mathrm{C}$ for $2 \mathrm{~h}$. Finally, the resultant powder was annealed in a furnace at a temperature of $300{ }^{\circ} \mathrm{C}, 600{ }^{\circ} \mathrm{C}$, or $900{ }^{\circ} \mathrm{C}$ for $2 \mathrm{~h}$ in order to increase the concentration of point defects. The powder was then stored in a desiccator ready for further use for a period of up to one month after production.

Physical characteristics of the synthesised nanoparticles were examined using various techniques. General morphologies were examined with a Hitachi SU 6600 FESEM scanning electron microscope (SEM) operating at $10.0 \mathrm{kV}$. A diffractometer (Siemens D-500) with a Cu anode operating at a wavelength of $0.15406 \mathrm{~nm}(\mathrm{Cu} \mathrm{K \alpha})$ was used to obtain X-ray diffraction (XRD) patterns. The diffractograms were recorded in the $2 \theta$ range from $20^{\circ}$ to $80^{\circ}$ and the diffractometer operated at $40 \mathrm{kV}$ and $30 \mathrm{~mA}$. Scherrer's equation was employed to determine the primary crystallite size of a given crystal phase based on the most intense diffraction peak. The Xray photoelectron spectroscopy (XPS) system utilised was a VG Microtech electron spectrometer at a base pressure of $1 \times 10^{-9}$ mbar. The photoelectrons were excited with a conventional $\mathrm{Mg} \mathrm{K}_{\alpha}$ $(\mathrm{h} v=1253.6 \mathrm{eV}) \mathrm{X}$-ray source and an electron energy analyser operating at a $20 \mathrm{eV}$ pass energy, yielding an overall resolution of $1.2 \mathrm{eV}$.

\subsection{Fabrication and Testing of Resistive Switching Devices}


A suspension of $\mathrm{CeO}_{2}$ annealed at $900^{\circ} \mathrm{C}(0.07 \mathrm{~g})$ was prepared in 2-propanol $\left(10 \mathrm{~cm}^{3}\right)$. This temperature was selected due to the higher concentration of point defects as can be confirmed with XPS results. Then $10 \mu \mathrm{L}$ of this suspension was placed on an aluminium or copper lap panel/plate (dimensions of $10 \mathrm{~cm} \times 2.5 \mathrm{~cm} \times 2 \mathrm{~mm}$ ). The clear advantage of this device is its ease of construction which is readily apparent in Fig.1. This suspension layer was then allowed to dry in a fume hood and another panel (either copper or aluminium) was clamped on top of the first

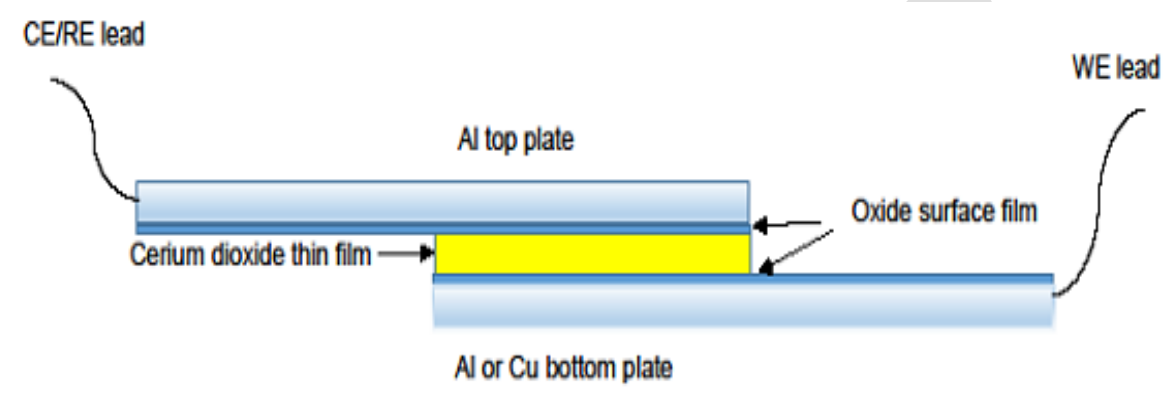

panel. An insulating pad ensured that both panels were insulated from the clamp. A computercontrolled potentiostat (CHI 600A) was used to control and monitor the device assembly where the reference and counter electrode (CE/RE) connections were linked to one panel (top electrode), while the working electrode (WE) was connected to the other (bottom electrode).

Fig.1 An expanded cross-sectional view of $\mathrm{Al} / \mathrm{CeO}_{2} / \mathrm{Al}(\mathrm{Cu})$ device (not drawn to scale). A thin film of $\mathrm{CeO} 2$ NP was placed between two plates which were carefully separated but connected electrically through the $\mathrm{CeO}_{2}$ thin film interlayer forming a sandwich-like assembly.

Using this equipment, above approximately $0.6 \mathrm{~V}$, the current became saturated (as it was above the potentiostat's current sensing capability). Consequently, potentials between $-0.6 \mathrm{~V}$ and $0,6 \mathrm{~V}$ were typically applied in this work, in order to prevent instrument current overloading. An AFM measurement of the $\mathrm{CeO}_{2}$ NP's layer indicated that it was $40 \mathrm{~nm}$ in thickness.

\subsection{Electrochemical Impedance Spectroscopic Analysis}

Electrochemical Impedance Spectroscopic was performed using a Solartron 1287 electrochemical system, together with a 1255B analyser and ZPlot and ZView (Scribner and Associates) software. A two-electrode configuration was adopted as in the case of the cyclic voltammogram (I-V) curves, with one electrode serving as the WE and the other a combined 
CE/RE. A frequency range of $100 \mathrm{kHz}$ to $0.1 \mathrm{~Hz}$ was employed. The instrument was calibrated with a separate equivalent circuit dummy cell using known values of each electrical component, confirming its operational performance.

\section{Results and discussion}

\subsection{Characterisation of $\mathrm{CeO}_{2}$}

Both crystal phases and crystallinity of the synthesised nanoparticles were determined by XRD measurements as shown in Fig. 2 (a). The XRD patterns of $\mathrm{CeO}_{2}$ powders are presented in this figure at three different annealing temperatures of $300{ }^{\circ} \mathrm{C}, 600{ }^{\circ} \mathrm{C}$, and $900{ }^{\circ} \mathrm{C}$ respectively. The eight peaks with $2 \theta$ values of $28.6^{\circ}, 33.2^{\circ}, 47.5^{\circ}, 56.4^{\circ}, 59.2^{\circ}, 69.9^{\circ}, 77.1^{\circ}$, and $79.8^{\circ}$ correspond to the (111), (200), (220), (311), (222), (400), (311) and (420) planes that can be

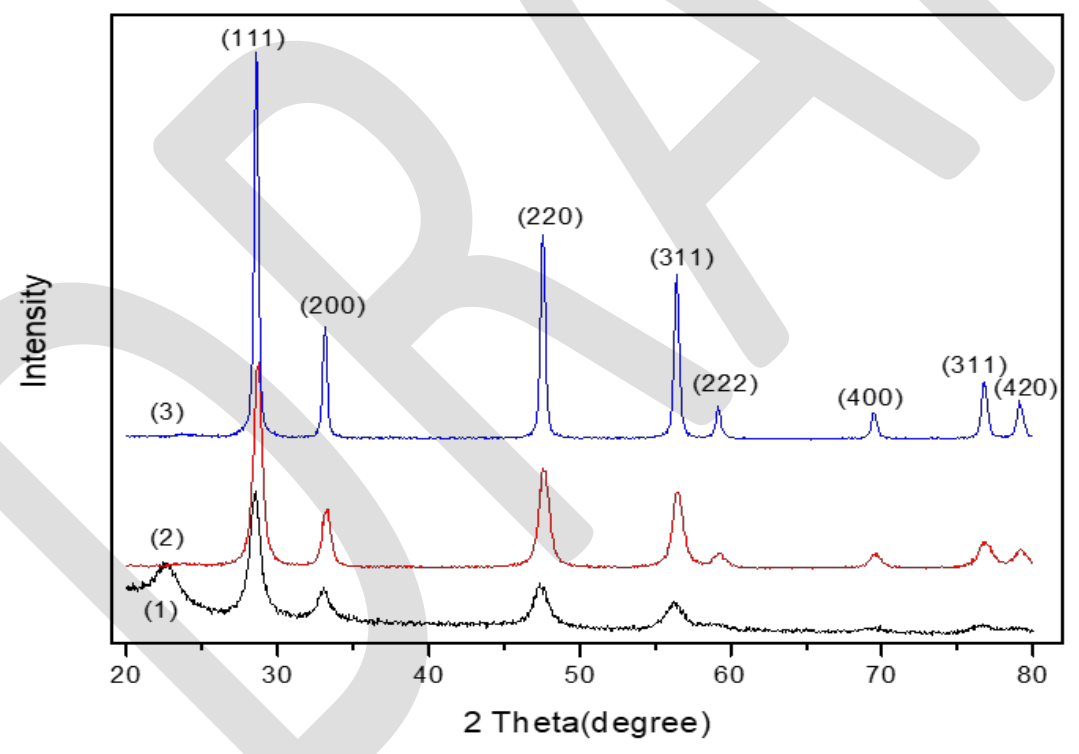

indexed as a face centred cube phase of crystalline $\mathrm{CeO}_{2}[42]$.

Fig. 2 XRD Diffractogram of $\mathrm{CeO}_{2}$ nanoparticles after annealing at (1) $300^{\circ} \mathrm{C}$ (2) $600^{\circ} \mathrm{C}$ and (3) $900^{\circ} \mathrm{C}$ respectively 
XPS analysis was carried out in order to quantify the surface chemical structures and the ionisation states of the synthesised $\mathrm{CeO}_{2}$ NPs An XPS scan is displayed in Fig. 3. Cerium 3d spectra were measured, in which the shifts in binding energies were calibrated using the $C$ 1s peak as a reference at a binding energy of $284.8 \mathrm{eV}$. The XPS spectra of the Ce 3d level were deconvoluted and separated into Ce 3d3/2 and Ce 3d5/2 peaks. The peaks in the range 875-895 $\mathrm{eV}$ were assigned to the $\mathrm{Ce} 3 \mathrm{~d} 5 / 2$ while peaks between 985-910 eV correspond to $\mathrm{Ce} 3 \mathrm{~d} 3 / 2$ levels. The software CasaXPS ${ }^{\circledR}$ was used to carry out the calculations of integrated areas of the peaks. Peaks were fitted with a Gaussian line shape over a Tougaard background. The assignment was made of $\mathrm{Ce}^{4+} 3 \mathrm{~d}$ component (3d5/2: $888.3 \mathrm{eV}$; 3d3/2: $\left.906.5 \mathrm{eV}\right)$ and $\mathrm{Ce}^{3+} 3 \mathrm{~d}$ component (3d5/2: $879.2 \mathrm{eV}, 891.1 \mathrm{eV}$; 3d3/2: $903.7 \mathrm{eV}$ ). The estimation of $\mathrm{Ce}^{3+} / \mathrm{Ce}^{4+}$ ratio was found to be $59.44 \%$ for $\mathrm{Ce}^{3+}$ and $40.87 \%$ for $\mathrm{Ce}^{4+}$. This indicates that $\mathrm{Ce}^{3+}$ was the predominant surface species. This is generally thought to be indicative of the presence of a substantial number of point defects, including oxygen vacancies in the underlying $\mathrm{CeO}_{2}$ crystal structure.

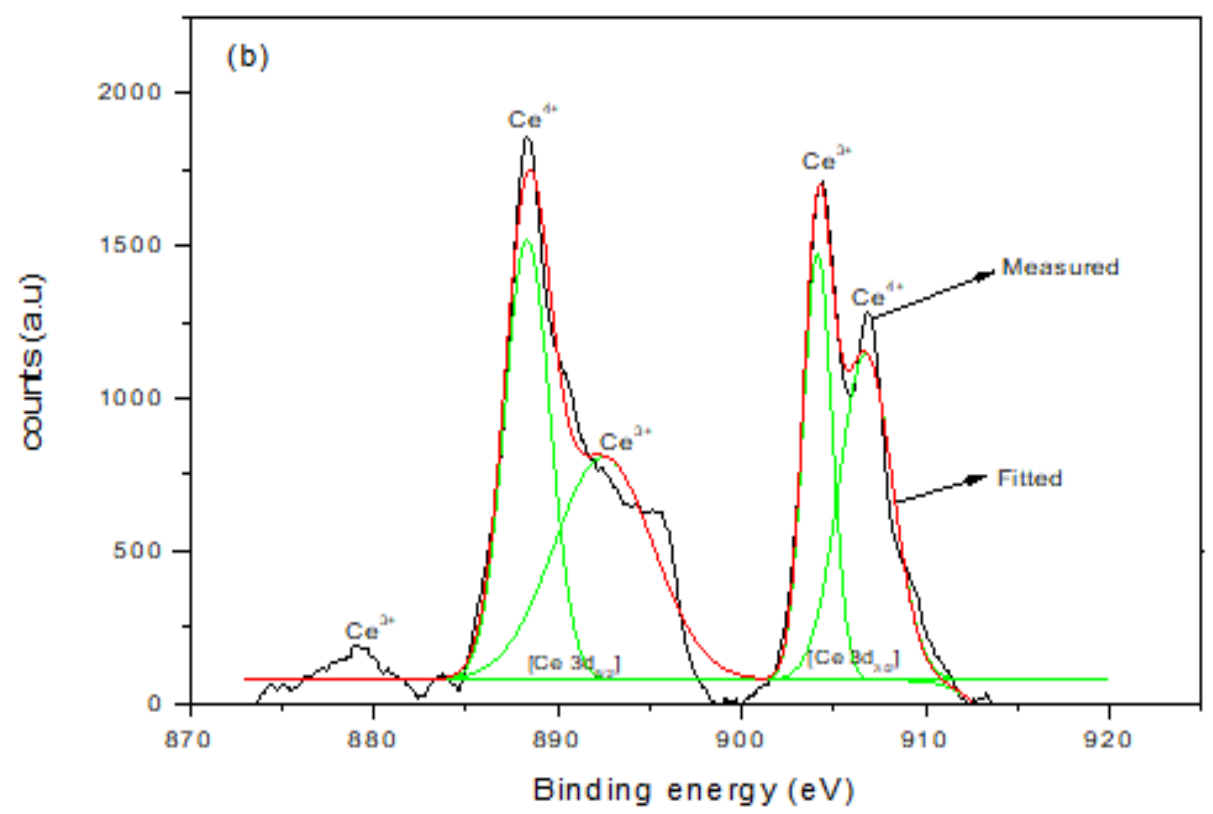

Fig. 3 XPS spectra of the as-prepared $\mathrm{CeO}_{2}$ annealed at $\overline{9} 00^{\circ} \mathrm{C}$.

From Scherrer’s formula (Eq.1) the average crystallite size (L) may be found as:

$$
L=K \frac{\lambda}{\beta} \cdot \cos \theta
$$


where $\lambda$ is the $X$-ray wavelength in nanometer $(\mathrm{nm}), \mathrm{K}$ is a constant related to crystallite shape, normally taken as 0.9 [43]. It can be taken as 0.89 or 0.9 for Full-Width Half Maximum (FWHM) of spherical crystals with cubic unit cells. $\beta$ is the peak width of the diffraction peak profile at half maximum height resulting from small crystallite size in radians. The crystallite size of $\mathrm{CeO}_{2}$ annealed at temperatures of $300{ }^{\circ} \mathrm{C}, 600{ }^{\circ} \mathrm{C}$ and $900{ }^{\circ} \mathrm{C}$ was calculated to be $2.41 \mathrm{~nm}, 8.8 \mathrm{~nm}$ and $26.6 \mathrm{~nm}$ respectively.

\subsection{Device Characterisation}

SEM images provided structural and morphological insights into the $\mathrm{CeO}_{2}$ nanoparticles. Figure 4(b) shows the $\mathrm{CeO}_{2}$ nanoparticles are aggregated (cf Figure 4(a)). Moreover, a dense population with small nanoparticles with a mean size of $35 \mathrm{~nm}$ on the surface of the substrate was observed.

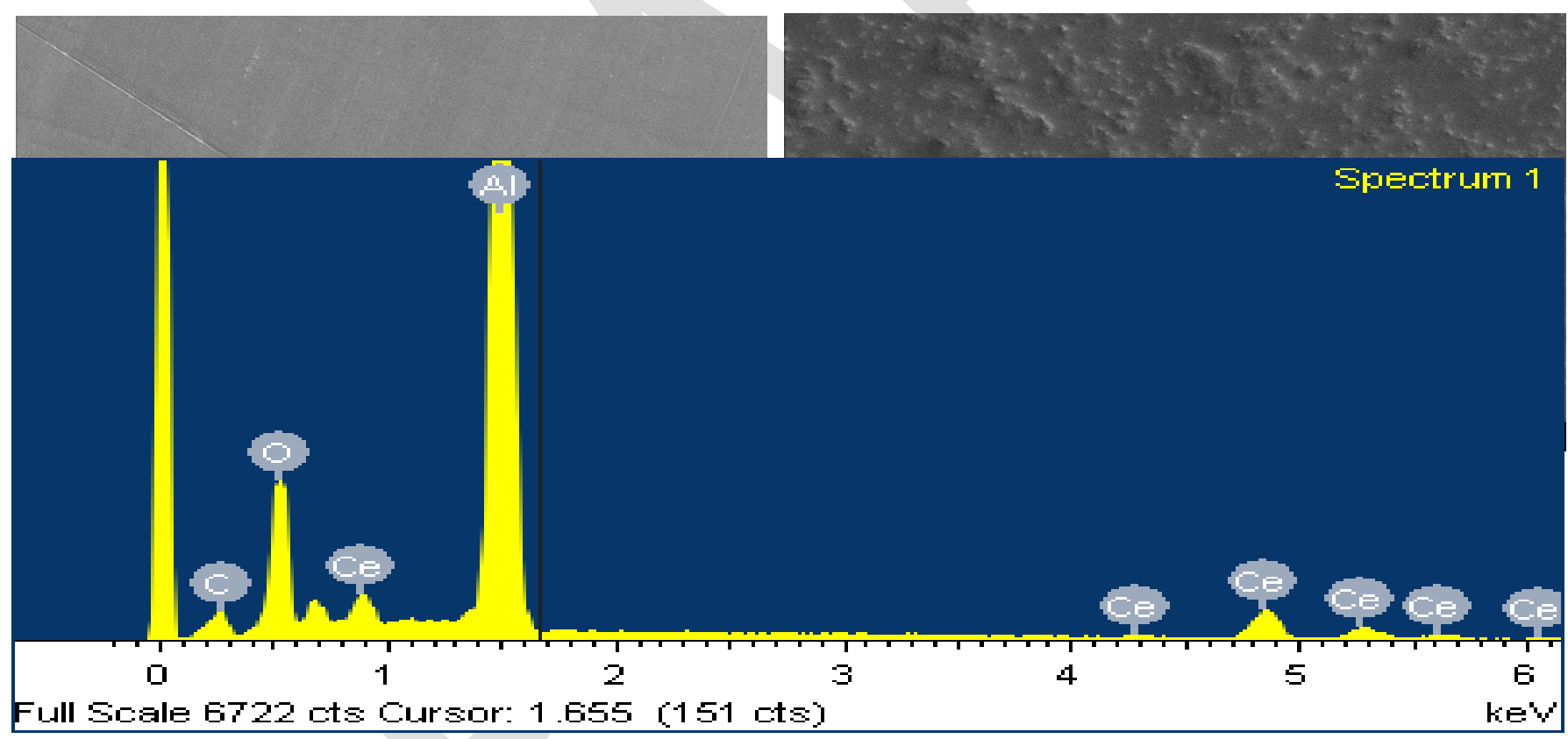

Fig. 4 (Top) SEM images of Aluminium lap shear before adding nanoceria (left). Image of Al plate after dropcasting $\mathrm{CeO}_{2} \mathrm{NP}$ (right). (Lower) SEM/EDS Elemental analysis of Al plate with drop cast $\mathrm{CeO}_{2} \mathrm{NP}$ (c) EDS data of $\mathrm{Al} / \mathrm{CeO}_{2}$ material. 
An EDS analysis is shown in figure 4(c). This image confirms the expected composition for the $\mathrm{Al}$ substrate coated with $\mathrm{CeO}_{2}$ with cerium, oxygen and aluminium all being detected, along with traces of carbon most probably from the carbon tab in the SEM chamber.

\subsection{Device Behaviour and Operational Mechanism.}

When cyclic voltammetry was applied to two aluminium panels clamped together, an Ohms law plot was the result. The limiting resistance was found to be $5 \Omega$. The same resistance was found when an aluminium panel was clamped to a copper panel.

Figure 5 shows typical current-voltage ( $I-V$ ) data of an $\mathrm{Al} / \mathrm{CeO}_{2} / \mathrm{Cu}$ assembly (a) in a 4 cycle cyclic voltammogram and an $\mathrm{Al} / \mathrm{CeO}_{2} / \mathrm{Al}$ assembly and (b) in a 12 cycle cyclic voltammogram respectively. This data was obtained from the imposition of a triangular potential sweep conducted at a scan rate of $10 \mathrm{mV} / \mathrm{s}$ over an applied potential range of -0.5 to $+0.5 \mathrm{~V}$. The initial potential in both cases was $0 \mathrm{~V}$. This figure demonstrates classic memristive switching behaviour, with a

transition from a high resistance state (HRS, ie. low current) to a low resistance (LRS, ie. high current) state. The potential was applied to the copper electrode with respect to the aluminium electrode in Figure 5 (a). The current obtained is much larger than those often reported in the literature since most memristive switching assemblies are prepared using microfabrication methods, yielding significantly smaller surface contact areas and substantially lower currents [12, 44]. However, for our devices, the contact area is much greater, of the order of $0.5 \mathrm{~cm}^{2}$. 

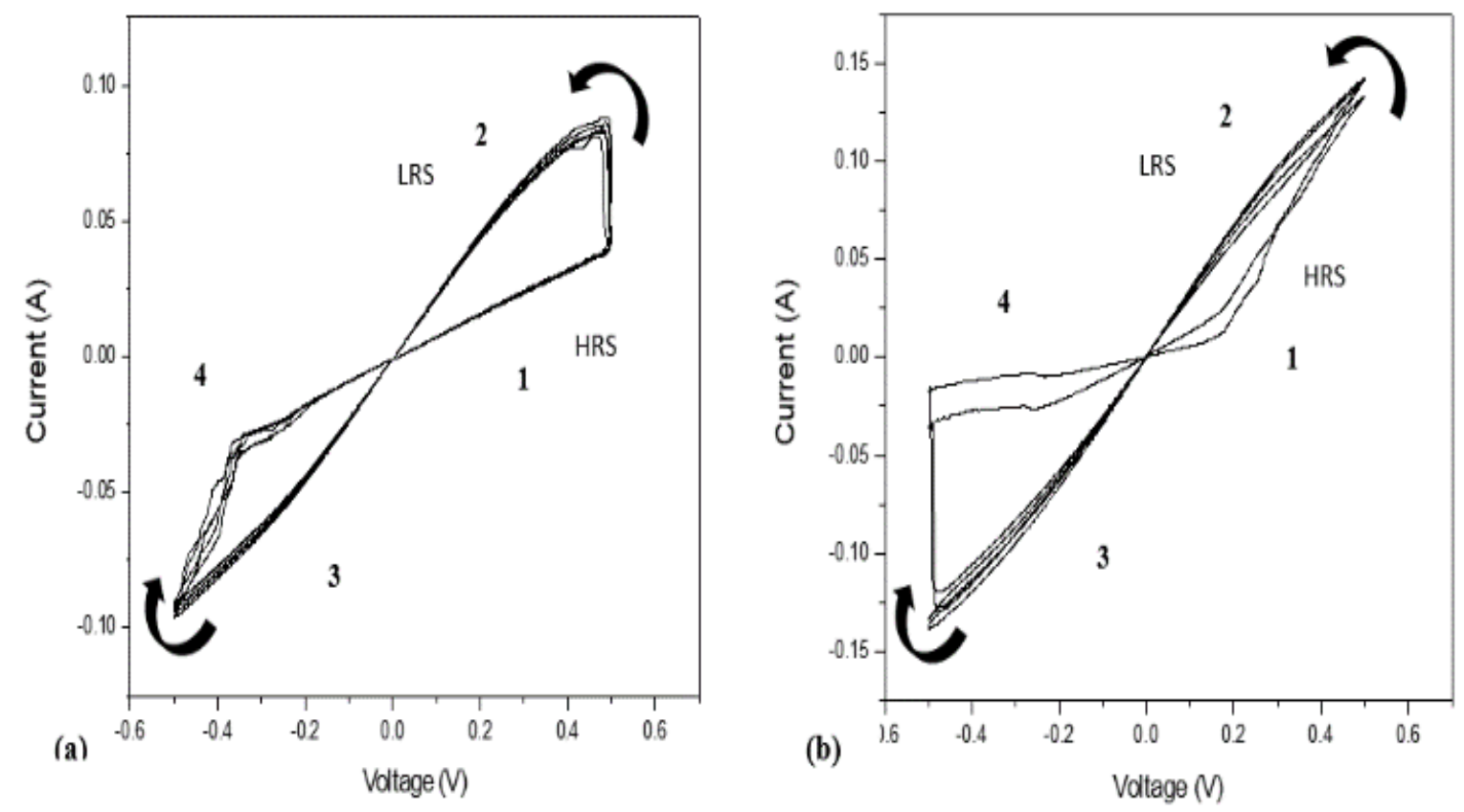

Fig. 5 A plot of current against potential displaying typical I-V behaviour of a bipolar resistive randomaccess memory (or memristor) of an $\mathrm{Al} / \mathrm{CeO} / \mathrm{Cu}$ assembly, (a) the $\mathrm{Cu}$ panel is $\mathrm{WE}$ and $\mathrm{Al}$ is $\mathrm{CE} / \mathrm{RE}$. (b) The I-V curve of an $\mathrm{Al} / \mathrm{CeO} 2 / \mathrm{Al}$ assembly with $\mathrm{Al} \mathrm{WE}$ and $\mathrm{Al} \mathrm{CE} / \mathrm{RE}$. Scan rate $=10 \mathrm{mV} / \mathrm{s}$ for each

In figure 5 two different bipolar curves $(I-V)$ are apparent. Figure 5 (a) (the $\mathrm{Al} / \mathrm{CeO}_{2} / \mathrm{Cu}$ assembly) shows a curved, largely symmetric switching behaviour, whereas in Fig. 5 (b), the $\mathrm{Al} / \mathrm{CeO}_{2} / \mathrm{Al}$ assembly shows a triangular curve that exhibits a clear hysteresis and asymmetric switching behaviour. For the sake of clarity, only 4 cycles are shown in Fig. 5 (a). In Fig 5 (b) the first 2 initial scans are overlaid together with the $11^{\text {th }}$, and $12^{\text {th }}$ consecutive scans.

It is proposed that the potential energy barrier for electrons produced at a metal/semiconductor interface or junction, which is effectively a Schottky barrier, could possibly account for the difference in the bipolar curves obtained for both devices. For the $\mathrm{Al} / \mathrm{CeO}_{2} / \mathrm{Cu}$ assembly (Fig. 5(a)), a p-type surface copper oxide layer can occur at the $\mathrm{Cu} / \mathrm{CeO}_{2}$ electrode/semiconductor interface resulting in a Schottky barrier with different characteristics from its $\mathrm{Al} / \mathrm{CeO}_{2}$ counterpart. A Schottky barrier contact was implicated at a $\mathrm{Cu} / \mathrm{BaTiO}_{3}$ interface within a perovskite-based memristive switching device comprising of a $\mathrm{Cu} / \mathrm{BaTiO}_{3} / \mathrm{Ag}$ assembly [45].

In addition, for the $\mathrm{Al} / \mathrm{CeO}_{2} / \mathrm{Al}$ device (Fig 5(b)) the possible effect of the aluminium oxide passive film layer, or probably even a more complex mixed-phase (hydrated aluminium oxide) 
should also be taken into account. Thus, a chemical reaction between the Al top/bottom electrode and the $\mathrm{CeO}_{2}$ NPs could also play a role in the operation of the breakdown of the memristive switching, since this been observed experimentally for $\mathrm{TiO}_{2}$ using advanced microscopic techniques [46]. This has been proposed by Jeong et al. [46] and Yang et al. [47] who suggested that there is an oxygen deficiency present in the comparable $\mathrm{TiO}_{2}$ nanoparticle thin layer It is thus likely that a similar situation occurs in the case of the $\mathrm{CeO}_{2}$ thin film layer. This contradicts the widely held view that oxygen vacancies at the metal-oxide interface play a critical role on the reversible switching between a high resistance state and a low resistance state [46, 47]. It should be noted that $\mathrm{Al} / \mathrm{CeO}_{2} / \mathrm{Al}$ is better represented as $\mathrm{Al} / \mathrm{Al}_{2} \mathrm{O}_{3}(\mathrm{OH}) / \mathrm{CeO}_{2} / \mathrm{Al}_{2} \mathrm{O}_{3}(\mathrm{OH}) / \mathrm{Al}$, e.g. with a hydrated aluminium oxide passive surface film on top of the aluminium. However, the conventional representation is $\mathrm{Al} / \mathrm{CeO}_{2} / \mathrm{Al}$. The two assemblies shown in Figure 5 are different systems and therefore would be expected to have different electrochemical characteristics. Similar asymmetric behaviour to that shown in Fig 5(b) was demonstrated by Gale et al. for an Al/sol-gel $\mathrm{TiO}_{2} / \mathrm{Al}$ resistive switching device [48].

Figure 6 shows an Electrochemical Impedance Spectroscopic (EIS) Bode plot recorded at an applied DC potential of $0.3 \mathrm{~V}$ and an AC amplitude of $10 \mathrm{mV}$. Whereas the $\mathrm{Al} / \mathrm{Al}$ control showed a constant frequency-independent impedance of less than $\sim 1 \mathrm{ohm}$, the $\mathrm{Al} / \mathrm{CeO}_{2} / \mathrm{Al}$ device demonstrated the existence of a transition to significantly higher impedance values in the frequency range between $251 \mathrm{~Hz}$ to $0.79 \mathrm{~Hz}$. In this frequency range the impedance rises up to 2 X $10^{6} \Omega$. Such behaviour was predicted by Abraham [49] who proposed a dual resistive switching between an HRS and LRS in memristor devices, similar to that observed in this work. This could be possibly be associated with changes in the operation of the Schottky barrier of the $\mathrm{CeO}_{2}$ nanoparticles immediately adjacent to the aluminium electrode. 


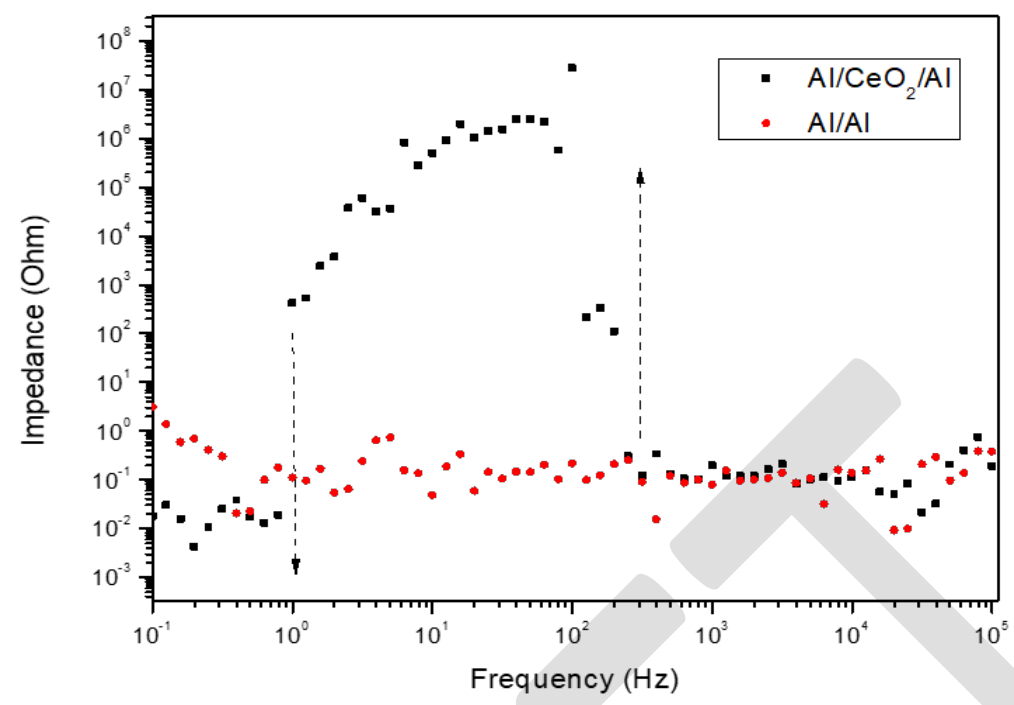

Fig. 6 EIS Bode plot of frequency against impedance displaying typical behaviour of a bipolar resistive random-access memory (or memristor) of an $\mathrm{Al} / \mathrm{CeO}_{2} / \mathrm{Al}$ assembly carried out at $0.3 \mathrm{~V}$ with a $\Delta \mathrm{E}$ of $10 \mathrm{mV}$ Scanned from $100 \mathrm{kHz}$ to $0.1 \mathrm{~Hz}$.

Cerium dioxide nanoparticles prepared by precipitation from an aqueous salt solution followed by annealing at elevated temperature are highly non-stoichiometric in nature. Such particles contain various point defects such as oxygen vacancies, cerium vacancies and cerium interstitials [50]. In order to explain the resistive switching mechanism of $\mathrm{CeO}_{2}$ based on the movements of electrons and holes, Kröger-Vink notation is utilised. In this notation $(\bullet \bullet)$ represents a double positive charge and ( $\left.e^{\prime}\right)$ signifies negatively charged electrons.

Thus, an oxygen ion in a normal lattice site can lead to the formation of a vacancy (with a double positive charge), along with the evolution of oxygen and the release of 2 electrons.

$$
\mathrm{O}^{x}{ }_{0} \leftrightharpoons \mathrm{V}_{\mathrm{o}}^{\bullet \bullet}+2 \mathrm{e}^{\prime}+1 / 2 \mathrm{O}_{2}
$$


Equation (2) explains why the presence of oxygen vacancies has been attributed to an ntype $\mathrm{CeO}_{2}$ semiconductor [51-53]. The notation of the lattice components according to both the Kröger-Vink notation used in solid state physics and the traditional chemical notation are presented in Table 1 for $\mathrm{CeO}_{2}$, adapted from an analogous oxide material, $\mathrm{TiO}_{2}$ [54].

Table 1. Notations used to denote various $\mathrm{CeO}_{2}$ lattice defect species along with the Kröger-Vink notation and net charge. Adapted from the semiconductor material $\mathrm{TiO}_{2}$ [54].

\begin{tabular}{|c|c|c|c|}
\hline $\begin{array}{l}\text { Traditional } \\
\text { Notation }\end{array}$ & Physical Presence & $\begin{array}{l}\text { Kröger-Vink } \\
\text { Notation }\end{array}$ & Net Charge \\
\hline $\mathrm{Ce}_{\mathrm{Ce}}{ }^{4+}$ & $\mathrm{Ce}^{4+}$ ion in cerium lattice site & $\mathrm{Ce}_{\mathrm{Ce}}^{\mathrm{x}}$ & Neutral \\
\hline $\mathrm{Ce}_{\mathrm{Ce}}{ }^{3+}$ & $\begin{array}{l}\mathrm{Ce}^{\mathrm{S}^{+}} \text {ion in the Cerium lattice site (quasi-free } \\
\text { electron) }\end{array}$ & $\mathrm{Ce}_{\mathrm{ce}}{ }^{\prime}$ & -1 \\
\hline $\mathrm{V}_{\mathrm{Ce}}$ & Cerium vacancy & $\mathrm{V}_{\mathrm{Ce}}{ }^{\prime \prime "}$ & -4 \\
\hline $\mathrm{Ce}_{\mathrm{i}}^{3+}$ & $\mathrm{Ce}^{\mathrm{S}^{+}}$ion in interstitial site & $\mathrm{Ce}_{\mathrm{i}}^{\bullet \bullet \bullet}$ & +3 \\
\hline $\mathrm{Ce}_{\mathrm{i}}^{4+}$ & $\mathrm{Ce}^{4+}$ ion in interstitial site & $\mathrm{Ce}_{\mathrm{i}} \bullet \bullet \bullet$ & +4 \\
\hline $\mathrm{O}_{\mathrm{O}}^{2-}$ & $\mathrm{O}^{2-}$ ion in oxygen lattice site & $\mathrm{O}_{\mathrm{O}}^{\mathrm{x}}$ & Neutral \\
\hline $\mathrm{V}_{\mathrm{O}}$ & Oxygen vacancy & $\mathrm{V}_{\mathrm{O}} \ddot{*}$ & +2 \\
\hline $\mathrm{O}_{\mathrm{O}}^{-}$ & $\begin{array}{l}\mathrm{O}^{-} \text {ion in oxygen lattice site (quasi-free } \\
\text { electron-hole) }\end{array}$ & $\mathrm{h}^{\circ}$ & +1 \\
\hline
\end{tabular}

Figures 7 and 8 show the currents obtained from the application of selected constant potentials (in $0.1 \mathrm{~V}$ increments) to the copper/aluminium electrode with respect to the aluminium electrode, for the $\mathrm{Al} / \mathrm{CeO}_{2} / \mathrm{Cu}$ assembly and for the $\mathrm{Al} / \mathrm{CeO}_{2} / \mathrm{Al}$ assembly respectively. The current evolution at each fixed potential was recorded for a period of $10 \mathrm{~s}$. The resulting constant currents indicate resistive behaviour. This confirms that the current is produced by the rapid movement of electrons or holes rather than by ionic species as it not dependent on $\mathrm{t}^{-1 / 2}$. However, the current behaviour is different when a positive potential is applied compared to when a negative potential is applied. In the case of the high negative potentials $(-0.4 \mathrm{~V}$ and $-0.5 \mathrm{~V})$, a slight initial current decay is evident before a steady-state current is attained as is evident in figure 7. 
(a)

(b)

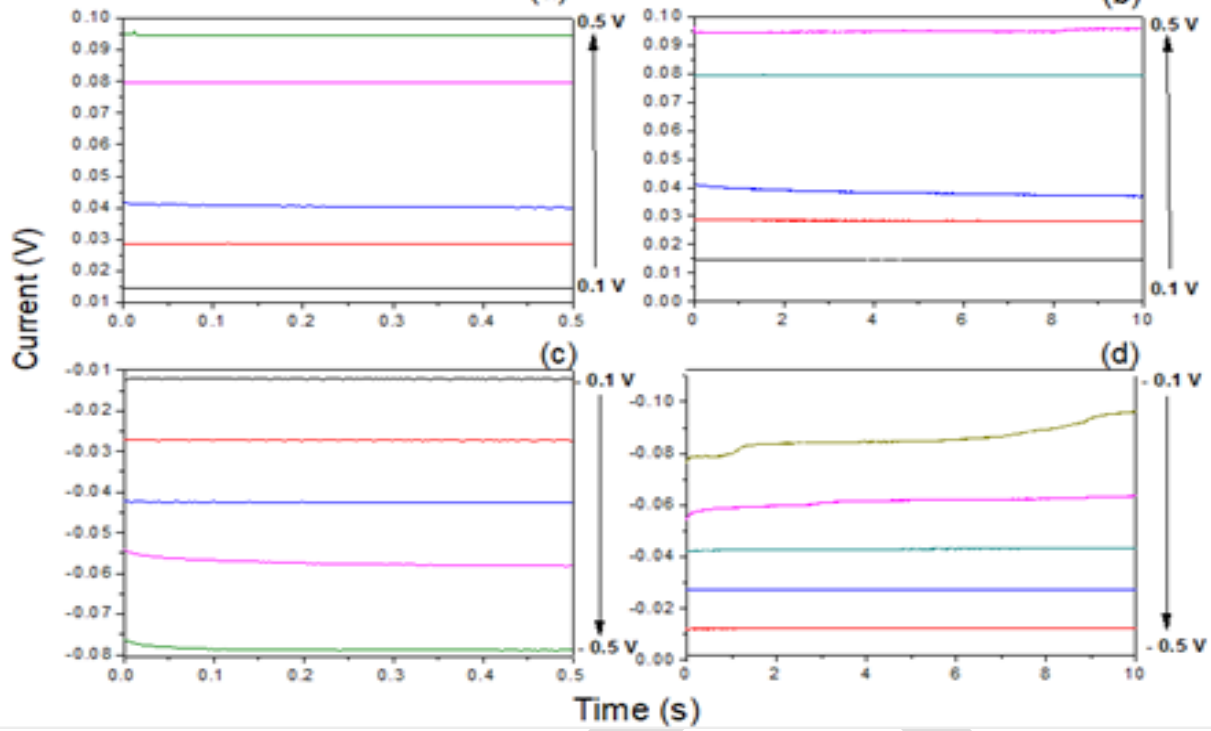

Fig. 7 Current transients at fixed potentials for 10 s and $0.5 \mathrm{~s}$ in $0.1 \mathrm{~V}$ steps ranging from $0.1 \mathrm{~V}$ to $0.5 \mathrm{~V}$ on top side (a) and respectively

(a)

to $-0.5 \mathrm{~V}$ on side for

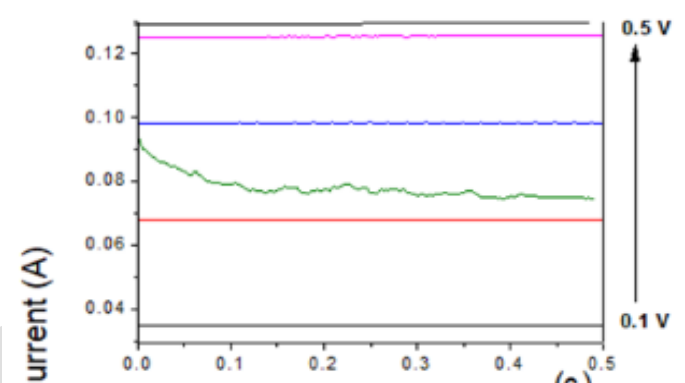

(c)

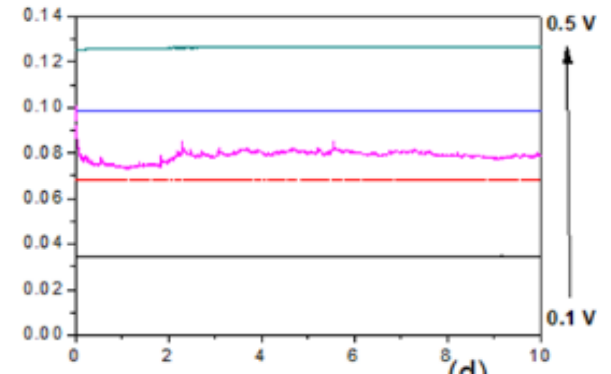

(d)

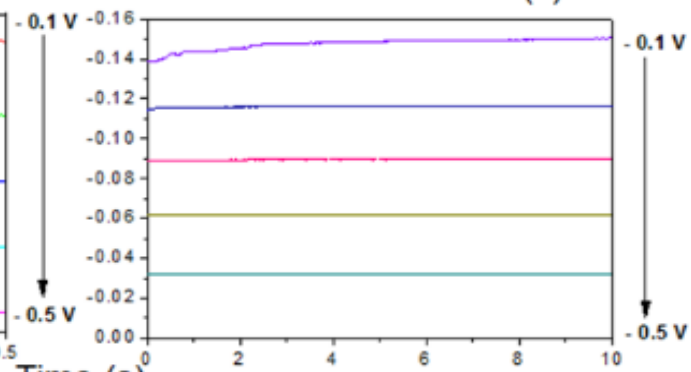

Time (s) and $-0.1 \mathrm{~V}$ the bottom

$\mathrm{Al} / \mathrm{CeO} 2 / \mathrm{Cu}$ (c) and (d). This data comes from the same device as that measured in Fig. 5 (a) 
Fig. 8 Current transients at fixed potentials for $10 \mathrm{~s}$ and $0.5 \mathrm{~s}$ in $0.1 \mathrm{~V}$ steps ranging from $0.1 \mathrm{~V}$ to $0.5 \mathrm{~V}$ on top side (a) and (b) respectively and $-0.1 \mathrm{~V}$ to $-0.5 \mathrm{~V}$ on bottom side for $\mathrm{Al} / \mathrm{CeO} 2 / \mathrm{Al}$ (c) and (d). This data comes from the same device as that measured in Fig. 5 (b).

Figure 8 displays the corresponding current-time behaviour for the $\mathrm{Al} / \mathrm{CeO}_{2} / \mathrm{Al}$ device, where once again the resulting constant current indicates a non-diffusional behaviour. The current is essentially steady, apart from the most positive potential, with some current noise evident at 0.3 V. Such constant currents are not observed for the movement of ionic species, only at p-n junctions, where the movement of electron and holes occurs [30]. As can be observed in Figures 7 (b), 8 (b) and 7(d), 8(d), the current is constant for the first few milliseconds. Such a linear current-time dependence supports the notion that a diffusion-controlled process involving ionic species is not occurring at the $\mathrm{Al}$ and $\mathrm{Cu}$ outer electrodes.

Rather than a mechanism involving ionic movement, it is suggested instead that in these macro-scale memristive switching devices, electron and hole movement forms a p-n junction which is forward-biased. Ultimately a low resistance state is attained and eventually a constant current observed at both positive and negative fixed potentials. Therefore when the thin film of $\mathrm{CeO}_{2}$ is placed between two outer electrodes in a memristor configuration (figure 1) and a positive potential is applied (region 1 in Figure 5 (a) and (b)), oxidation happens at the anode (equation (2 or 3)) to form a p-type $\mathrm{CeO}_{2}$ since the $\mathrm{V}_{\mathrm{o}}^{\bullet \bullet}$ remain, while the electrons pass into the electrode. In figure 5 (a) and (b) the initial potential is zero volts and region 1 corresponds to the initial sweep. It can be seen that the current is small since the $\mathrm{CeO}_{2}$ is mostly resistive at this stage. However, at the anode, the following oxidation reaction takes place (analogous to equation (2)): 


$$
\mathrm{O}^{2-} \rightarrow \mathrm{O}_{2}+2 \mathrm{e}^{-}
$$

Fig. 9 Schematic representation of the transition from HRS semiconductor in region 1 (and region 4) of I$\mathrm{V}$ scans depicted in Fig 5 (top) to conducting LRS (bottom) responsible for the increase in current in region 2 (and region 3) of Fig 5.

This leads to a p-type semiconductor forming close to the anode. Such generation of oxygen at the anode of memristive switching devices has been seen experimentally $[47,48,56]$. This reaction can be considered as a half cell reaction, typical of that occurring in an electrolytic type of electrochemical cell. It has also been suggested that oxygen species can react directly with $\mathrm{Al}$ to form oxygen vacancies and an aluminium oxide; thus [48, 55]

$$
2 / 3 \mathrm{Al}+\mathrm{O} \rightarrow \mathrm{V}_{\mathrm{O}}^{\bullet \bullet}
$$

(4)

Simultaneously an reduction reaction cathode yielding (equation 5). Such process (equation

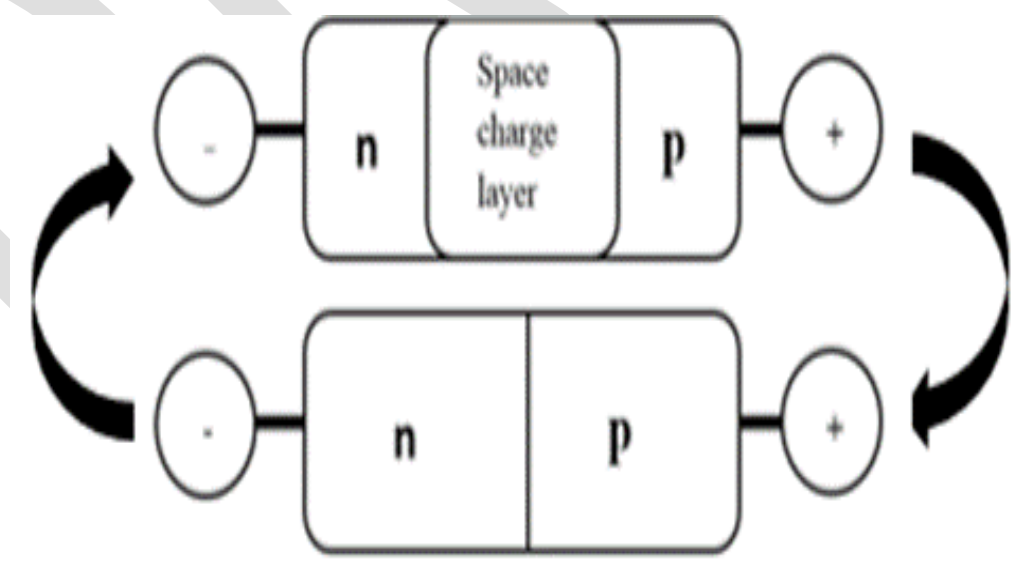
been reported by Younis et al. (11] and by Gao et al [22], both for $\mathrm{CeO}_{2}$.

$$
\mathrm{Ce}^{x}{ }_{C e}+\mathrm{e}^{-} \rightarrow \mathrm{Ce}_{\mathrm{ce}}{ }^{\prime}
$$

$+2 \mathrm{e}^{-}+1 / 3 \mathrm{Al}_{2} \mathrm{O}_{3}$

electrochemical occurs at the an n-type region a reduction 5) has previously 
In region 1 in figure 5 (a) and (b) at this stage, there is a movement of $\mathrm{O}^{2-}$ toward the anode or the movement of oxygen vacancies toward the cathode. Previous models in a $\mathrm{TiO}_{2} \mathrm{memristive}$ switching device comprise a conducting region adjoining an insulating region without acknowledging the reduction of $\mathrm{Ti}^{4+}$ forming $\mathrm{TiO}_{2-\mathrm{x}}$. However, as shown in Figure 9 (top) there is still an insulating region between the two semiconducting regions, which limits the current to low values, indicative of a high resistance state (HRS). As the potential is swept the semiconducting regions extend and once they meet, as shown in the lower part of Figure 9, a forward biased p-n junction is formed and the current thus increases dramatically [30, 40]. It has been proposed that the transition from n-type to p-type conduction can take place at low temperatures [57]. The creation of a p-n junction has been reported in a $\mathrm{CeO}_{2-x}$ electrolyte [58].

In contrast ionic conduction only becomes significant at high temperatures, often above $500^{\circ} \mathrm{C}$ which further supports the notion that the charge is carried by electrons and holes, rather than by ions in these devices operating at ambient temperatures [57]. As a consequence of this, a constant current is obtained at a constant potentials as displayed in Figures 7 and 8. If mass transport of $\mathrm{O}^{2-}$ was responsible for the measured current shown in Figures 7 and 8 a decrease in current would be expected as a consequence of the consumption of $\mathrm{O}^{2-}$ during the scan/device operation.

As the potential is swept back to zero volts (region 2 in Figure 5 (a) and (b)) there is still an enhanced current (LRS); however, since the driving force decreases (e.g. the potential becomes less), there is a decrease in the current. Once the polarity is changed, there is an immediate reversal of reactions (3) and (5). As the potential is swept more negative the rates of the two reactions increase and there still is an enhanced current as the majority of the device is still semiconducting. In region 3, the semiconducting regions that were created in regions 1 and 2 are slowly converted back to an insulating state. At the switching potential, corresponding to a decrease in the concentration of $\mathrm{O}_{2}$ and $\mathrm{Ce}_{\mathrm{ce}}$ ', the current drops dramatically as the device returns to its insulating state (HRS). In region 4 the current is small, since the device is primarily now in an insulating state.

The $I-V$ plot shown in Figure 5 (b) is not symmetric; this has also been reported in other memristor devices produced micro lithographically $[44,45]$. Indeed, a characteristic of our device is its simplicity; it can be produced without vacuum or microlithographic techniques. Thus, it is a platform that can be modified readily using inkjet [8] or screen-printing techniques [10] or other methods including spin coating, spray coating and blade coating [58]. In fact, most memristive 
switching systems reported in the literature use small scale electrodes (of the order of micrometres or smaller) separated by thin (nanometre-sized) layers. In these assemblies' defects such as surface defects, dislocations and grain boundaries may all play a significant role in their operation $[60,61]$. It is also worth noting that the imposition of a high electric field (e.g. more than $10^{7} \mathrm{~V} / \mathrm{m}$ ) can lead both to the creation of oxygen vacancies (equation 2) and to the movement of ionic and defect species in close proximity to an electrode, thereby promoting the reactions described in equations 2 to 5. Evidence for this non-thermally induced point defect production and response to a high electric field has come from studies involving cerium oxides [62,63]. The occurrence of high temperatures due to joule heating or some other localised thermal effect was refuted by Munjal and Kharee [55] in their work and also by $\mathrm{Li}$ et al [63] in their study of $\mathrm{CeO}_{2}$ thin film memristive behaviour.

While memristive switching behaviour is seen for the initial scans in Fig. 5, it is not shown after repeated consecutive cycles. Eventually the response changes to that of a pure resistor, indicating a change in the mechanism to ohmic conduction, as reported elsewhere [3]. In this case it is possible that in the absence of a high formatting or SET potential (larger than $1 \mathrm{~V}$ ) the levels of defects such as oxygen vacancies created within the high elctric field were insufficient to sustain the memristive switching in the macro-scale $\mathrm{CeO}_{2}$ device, resulting in destruction of the p$\mathrm{n}$ junction over time. Alternatively as the device studied in this work was exposed to laboratory air, it is also feasible that oxygen and moisture access may have played a role in the loss of memristive switching behaviour through alteration of the electrodes' surface chemistry over time [64]. Others have however reported high stability of more conventional $\mathrm{CeO}_{2}$ based memristive switching assemblies [14].

\section{Conclusions}

Crystalline cerium dioxide nanoparticles were prepared by a facile precipitation method and characterised using a variety of methods. When drop-cast as a thin film and placed between two conductive $\mathrm{Al} / \mathrm{Al}$ or $\mathrm{Al} / \mathrm{Cu}$ plates in a macro-scale assembly the prepared nanoceria exhibits resistive switching behaviour with a certain HRS/LRS characteristic. The memristive-switching device behaviour is explained in terms of an electrolytic cell involving point defect chemistry and semiconductor electrochemistry utilising electron and hole movement within the $\mathrm{CeO}_{2}$ thin film interlayer. This new electrolytic cell/semiconductor model accounts for the initial changes in the current-potential behaviour of such devices, which may decay over time back to a normal ohmic 
resistive state. This decay is possibly accounted for by the destruction of a conductive p-n junction over time, which is more readily apparent in a macro-scale device.

\section{Conflicts of Interest}

There are no conflicts of interest to declare.

\section{Acknowledgements}

The authors gratefully acknowledge the award of a DIT Fiosraigh Dean of Graduate Studies award to R C de Carvalho and participation in COST Action MP 1407 (e-MINDS).

\section{References}

1 E. Gale, Semicond.Sci. Tech. 2014, 29, 104004

2 A. Younis, D.Chu, I. Mihail, S. Li, Appl. Mater. Interf. 2013, 5, 9429

3 J. Yoo, K. Lee, A.Tighineanu, P. Schmuki, Electrochem. Comm 2013, 34 , 177

4 A Sawa Mats Today 2008 11, 628

5 S. Seo Appl. Phys. Lett. 2004, 85, 5655

6 B Gao, S Yu, N Xu, L F Liu, B Sun, X Y Liu, R Q Han, J F Kang, B Yu, Y Y Wang, IEEE Electronic Devices Meeting, Dec 2008, 1

7 D. Chu, A. Younis, S.Li, J. Phys. D: Appl. Phys. 2012, 45, 355306

8 Z. Yu, X Qu, W. Yang, J. Peng, Z. Yu, J. Alloys Compounds 2016, 688, 294

9 N. Duraisamy, N.M. Muhammad, H.-C. Kim, J.-D. Jo, K.-H. Choi, Thin Solid Films 2012, 520, 5070

10 D.H. Lien, Z.K. Kao, T.-H Huang, Y.C. Liao, S.C. Lee, J.H. He, ACS Nano 2014, 8, 7613

11 A. Younis, D. Chu, S Li, J. Phys. D: Appl. Phys. 2012, 45, 355101

12 A. Younis, L. Zhang, D. Chu, S. Li, Appl. Phys. Lett 2016, 108, 033506

13 M. Ismail, E. Ahmed, A. M. Rana, F. Hussain, I. Talib, M. Y. Nadeem, D. Panda, N.A. Shah, ACS Appl. Mater, Interfaces 2016, 8, 6127

14 C. C. Hsieh, A. Roy, A. Rai, Y. F. Chang, S. K. Banerjee, Appl. Phys. Lett. 2015, 106, 173108

15 W. Haynes, T. Bruno and D. Lide, CRC Handbook of Chemistry and Physics, CRC Press, (2015) Boca Raton, FL, $96^{\text {th }}$ Ed

16 K. Ghillanyona, D. Galusek, Ceramics Sci Tech Mat Prop 2011, 2, 1125

17 A. Younis, D. Chu and S. Li, Functionalized Nanomaterials 2016, 3, 1064 
18 D.B. Strukov, R.S Williams, Appl. Phys. 2009, 94, 515

19 D.B.Strukov, G.S.Snider, D.R.Stewart, R.S.Willians, Letters, Nature 2008, 453, 80

20 T.D.Dongale, K.P.Patel, P.K.Gaikwad, R.K.Kamat, Mater. Sci. in Semicond. Proc. 2015, 38, 228

21 L.Chen, C.Li, T.Huang, H.G. Ahmad, Y.Chen. Phys. Lett. A. 2014, 378, 2924

22 P.Gao, Z. Wang, W Fu, Z. Liao, K.Liu, W.Wang, X.Bai, E.Wang, Micron 2010, 41, 301

23 C.Ye, J.Wu, G.He, J.Zhang, T.Deng, P.He, H.Wang, J.Mat. Sci. Tech. 2016, 32, 1

24 F.Pan, S.Gao, C.Chen, C.Song, F.Zeng, Mater. Sci. Eng. Res 2014, 83, 1

25 V. Senthilkumar, A. Kathalingam, V. Kannan, J.K Rhee, Microelectronic.Eng. 2012, 98, 97

26 K.Szot, W.Speier, G.Bihlmayer, R.Waser, Nature Materials, 2006, 5, 312

27 T Salaoru, A Prodromakis, A Khiat, C Toumazou, Appl. Phys. Lett 2013, 102, 13506

28 D.Kalaev, E.Yalon, I.Reiss, Solid State Ionics 2015, 276, 9

29 J. Nowotny, M.A Alim, T Bak, M S Idris, M. Ionescu, K.Prince, M.Z Sahdan, K. Sopian, M.A.M Teridi, W. Sigmund, Chem Soc Reviews 2015, 44, 8424

30 R.C. de Carvalho, A.J. Betts, J.F. Cassidy, J Solid State Electrochem 2019, 23, 1939

31 M.H.Lee, K.M.Kim, G.H.Kim, J.Y. Seok, S.J.Song, J.H.Yoon, C.S.Hwang, Appl. Phys. Lett, 2010, 98, 152909

32 J. Blasco, N.Ghenzi, J.Sué, P.Levy, E.Miranda, Microelectron. Reliability 2015, 55, 1

33 E.W Lim, R. Ismail, Electronics 2015, 4, 586

34 L.C.T Shoute, N.Pekas, Y.Wu, R.L.McCreery, Appl. Phys. A 2011, 102, 841

35 J.Wu, R.L.McCreery, J.Electrochem. Soc. 2009, 156, 29

36 J.F.Cassidy, D.Fox, A.J.Betts, J. Solid State Electrochem. 2016, 20, 1229

37 I Valov, ChemElectroChem, 2014, 4, 26-36

38 W Sun, B Gao, M Chi, Q Xia, J. Yang, H Qian H Wu, Nature Comms 2019, 10, 3453

39 R Waser, J Nanosci Nanotech 2012, 12, 7628

40 R Waser, Dittmann, G Staikov and K Szot, Advan. Materials 2009, 31, 2632

41 P. S. Madhusudana, K. Mohanta, S. K. Batabyal, J Solid State Electrochem 2019, 23, 1307

42 H. Balavi, S.S.Isfahani,M.M. Zindabad, M.Edrissi, Powder Technol 2013, 249, 549

43 A. Monshi, M.R.Foroughi, M.R.Monshi, World J. of Nano Sci. and Eng. 2012, 2, 154

44 E. Gale, R. Mayne, A. Adamatzky, B.de Lacy Costello, Mater. Chem. Phys. 2014, 143, 524

45 L. J. Wei, Y. Yuan, J. Wang, H. Q. Tu, Y. Gao, B. You and J. Du, Phys. Chem. Chem. Phys, 2017, 19, 11864 
46 H.Y.Jeong, J. Y. Lee, S.Y. Choi, J. W. Kim. Applied Phys Letters 2009, 95, 162108

47 J. J. Yang, F. Miao, M. D. Pickett, D. A. A. Ohlberg, D. R. Stewart, C. N. Lau, and R. S. Williams, Nanotechnology 2009, 20, 215201

48 E. Gale, D. Pearson, S. Kitson, A. Adamatzky, B.de Lacy Costello, Mater. Chem. Phys. 2015, 162, 20

49 I Abraham, Sci Reps, 2018, 8, 10972

50 A.Tschope, W.Liu, M.F.Stephanopoulos, J.Y.Ying, J. Catalysis 1995, 157, 42

51 Y-M Chiang, E B Lavik, I Kosacki, H L Tuller, J Y Ying, Appl. Phys. Lett. 1996, 69, 185

52 S Gangopadhyay, D M Frolov, A Masunov, S Seal, J Alloy Compd 2014, 584, 199

53 K Kaviyarasu, Xolilie Fuku, Genene T Mola, E Manikandan, J Kennedy, M Maaza, Mats. Letts, 2016, 183, 351

54 M.K. Nowotny, L.R. Sheppard, T.Bak and J. Nowotny, J. Phys. Chem. C. 2008, 112, 5275

55 S Munjal and N Khare, Sci Reports, 2017, 7, 12427

56 C. S. Dash, S Sahoo, S Prabaharan, Solid State Ionics 2018, 324, 218

57 J. A. Kilner, Solid State Ionics 2000, 129, 13

58 B Wang, B. Zhu, S Yun, W Zhang, C Xia, M Azfal, Y Cai, Y Liu, Y Wang H Wang, NPG Asia Mater, 2019, 11, 51

59 Y Shan, Z Lyu, X Guan, A Younis, G Yuan, J Wang, S Li T Wu Phys. Chem. Chem. Phys., 2018, 20, 23837

60 Y Ding, Y Chen, K C Pradel, M Liu, Z Lin Wang, J Appd Phys 2016, 120, 214302

61 L.N. Liu, C.H. Zang, B. Wang, W. Su, H.Y. Xiao, D.M. Zhang, Y.S.Zhang, Vacuum, 2020, 173, 109128

62 P. Gao, Z. Kang, W. Fu, W. Wang, X. Bai, E. Wang, J. Am. Chem. Soc. 2010, 132, 12, 41974201

63 X. Li, K. Qi, M. Sun, Q. Huang, Z. Xu, W. Wang, X. Bai, Appl. Phys. Lett. 2015, 107, 211902

64 S. Tappertzhofen, I. Valov, T. Tsuruoka, T. Hasegawa, R. Waser, M. Aono, ACS Nano 2013, 7, 7, 6396-6402 